\title{
Gracias Señor
}

\author{
Gracias Señor
}

Mariângela Alves de Lima'

Mariângela Alves de Lima

Pesquisadora e crítica de teatro.

1 O artigo foi publicado originalmente nos Cadernos Cebrap, São Paulo, n. 2, p. 149-152, 1972.

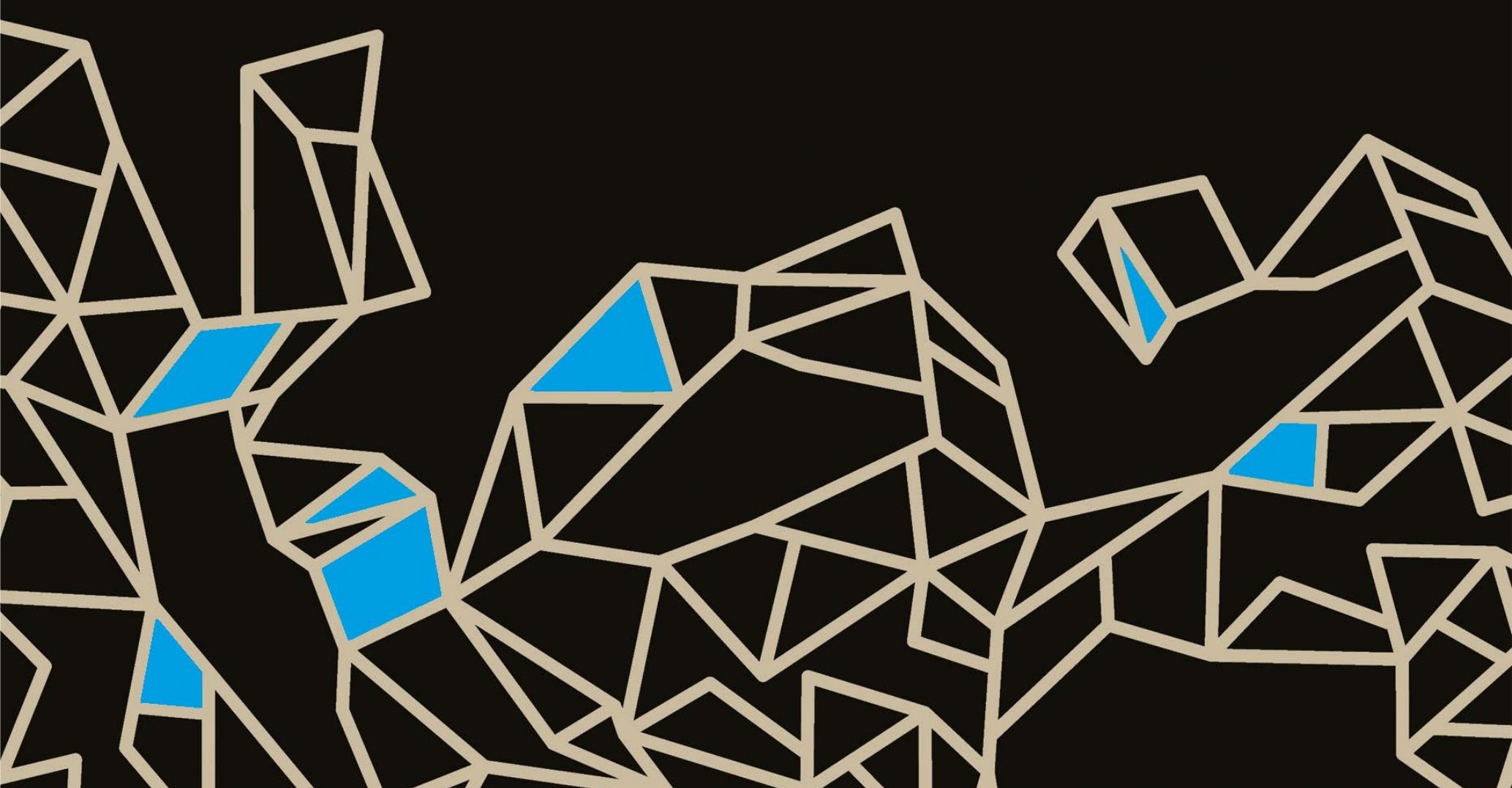


Pode o teatro transmitir ao público uma consciência teórica? Entre outras coisas, esse seria um objetivo possível. Em Gracias Señor, entretanto, os efeitos que o Oficina pretende obter de seu público ultrapassam os limites da instrução teórica. Para o Oficina não interessa mais atingir apenas o nível consciente da personalidade. Em 1972 o avanço político do grupo inclui uma outra forma de abordagem do fenômeno político. Uma abordagem que considera a organização do sistema introjetada na personalidade individual, atuando inclusive ao nível do inconsciente.

Assim o fenômeno político é focalizado a partir de sua célula primária de manifestação visível: o comportamento. Esse seria o primeiro índice de avaliação de uma situação política. E uma das coisas que o teatro pode fazer é criar uma situação em que o comportamento coletivo se manifeste, sob a impunidade aparente de uma situação fictícia. Isto é teatro. Apenas teatro.

Agora que estamos devidamente protegidos pelo estar no teatro, que tal seria reproduzir nossa vida cotidiana? Chegamos até a aula de esquizofrenia. O que acontece com um indivíduo que vivencia apaticamente as determinações do sistema? Primeiramente transforma-se em um catatônico como indivíduo. Gracias Señor realiza nesse momento a ilustração de um processo. Todas as reações individuais diferenciadas, desconformes com a planificação do sistema, são niveladas até a obtenção de um rendimento ótimo. Ótimo de acordo com as aspirações do mestre. E o que deseja exatamente o mestre? Além do extermínio da diferença, o objetivo é a redução do imaginário, das associações inconscientes que preservam as características individuais. No momento em que repetem a lição, os alunos são a lição.

Qualquer possibilidade de atuação "rebelde" desaparece nessa identidade entre o ser e a emissão verbal mecanizada.

Quando consegue a obediência absoluta, o mestre-sistema atingiu seu objetivo. Está satisfeito. Conclusão que não pode ser das mais animadoras. O sistema é sempre voltado para si mesmo, e se realiza na autogratificação. A imposição da catatonia é o meio e o fim.

Gracias Señor retoma o contato com a plateia. Realizamos a lobotomia? Resposta: não.

Até aqui a conclusão seria de que a preservação da individualidade é a arma eficaz para defender-se contra o monstro antisséptico que é a sociedade 
de consumo. Nesse caso, o melhor a fazer seria reinventar a Idade da Pedra na ilha de Marajó. Entretanto, uma das características do trabalho do grupo é a de não se preocupar muito com armas defensivas.

Considerando a trajetória do Oficina, desde 1967, a comunidade marajoara seria realmente uma conclusão demasiadamente ingênua. Da mesma forma que não falta ao grupo uma intuição estética, jamais Ihe faltou uma coerência entre a inauguração de um estilo e a justificativa política dessa nova forma. A intenção não é justificar Gracias Señor pela oportunidade histórica dos trabalhos anteriores. Apenas salientar que, como grupo, o Oficina se manteve sempre preocupado com a avaliação ideológica de seu público. Sabe, portanto, que as opções são difundidas simultaneamente com a propaganda de novos invólucros de sabonete.

Com Gracias Señor, o Oficina pretende reproduzir a situação de fato. A abertura para as intervenções do público indica já como o Oficina encara esse público, uma coletividade incapaz de refletir racionalmente sobre as propostas. Dessa forma, o espetáculo é estruturado a motivar inconscientemente a uma participação ou agressão. A interferência da plateia será, previsivelmente, emocional.

Como deixar passar em brancas nuvens uma oportunidade de manifestar-se? Essa é a cenourinha que Gracias Señor coloca na frente do burro. $\mathrm{O}$ espectador faz assim espetáculo e, fazendo-o, conta sua própria história com cores mais definitivas.

Diariamente o slogan se exerce sobre esse público indo comprar, organizando o lazer, modelando a vida como uma forma de indução absoluta. Durante o espetáculo a plateia comprova a extensão do processo repetindo frases como "inteligência é burrice". Gritam com convicção, com a mesma apaixonada emissão que precede as escaladas de guerra.

Se oferecemos um estímulo adequado, seguindo o processo de slogan, as reações serão imediatas e passionais. Gritarão qualquer coisa. Como separar, portanto, o político do emocional? Desencadeando no espetáculo as reações introjetadas pela cultura, Gracias Señor não está mostrando o slogan, mas as consequências mais extremas de uma uniformização sistemática. Enquanto grita «inteligência é burrice», o público está liberando o que pensaria sobre sua própria vivência, se ainda tivesse condições para 
refletir. Durante o espetáculo pode realizar o negativo do processo. Sem dúvida uma medida de emergência. Que o Oficina considera como uma contraproposta para as reduzidas possibilidades que esse público teria de fazer reflexões a longo prazo.

Estimulando as reações do público, o espetáculo concretiza aproximadamente o tipo de vida dos espectadores. $O$ espaço de teatro se transforma em um local para o exercício da vida, o que só pode ser feito através de estímulos e processos de condução análogos aos da experiência cotidiana. Gracias Señor opera assim como um laboratório de amostragem da nossa pequena burguesia. Nossos pequenos burgueses esclarecidos, sintonizados com a vanguarda teatral.

Todos os dados que emergem à tona durante essa experiência altamente emotiva são, é claro, passiveis de uma análise posterior. Mas o que pode ser feito depois do espetáculo não é exatamente o objetivo de Gracias Señor. As transformações possíveis devem ocorrer no presente do espetáculo.

A confrontação já é uma forma de questionamento. Entre os diversos momentos do espetáculo há cortes deliberados em que o espectador é abruptamente remetido à consciência das emoções que partilhou através da condução emocional. Invariavelmente as rupturas conduzem a uma investigação das alternativas de escapatória para uma situação opressiva. Alternativas que apontam sempre uma saída para fora do teatro,

$A$ ideia é oferecer simultaneamente a vivência e a reflexão. $E$ remeter $O$ espectador de volta à ação. Por mais empática que possa ser a sua estrutura dramática, a trajetória de Serafim Ponte Grande está condenada a um patético extermínio. Dentro do panorama que o público delineia durante o espetáculo, Serafim não é mais possível. O homem só, revoltado contra a opressão, está condenado ao suicídio, jamais à liberação.

Em Gracias Señor a sugestão de liberdade tem características bem diversas das propostas de isolamento em comunidades paradisíacas. $O$ espaço fora do teatro é geograficamente bem próximo do teatro.

O trabalho do Oficina apresenta urna realidade com maior eficiência do que propõe soluções. Mas há uma pergunta que o grupo dirige ao público no início do espetáculo: o que querem de nós, artistas? Qual é o papel que a arte desempenha em um processo de transformação? Pode o teatro apresentar 
soluções? E, no atual estágio de condicionamento que se constata durante o espetáculo, é possível pensar racionalmente em soluções?

As respostas existem em meios-termos plausíveis, bem menos radicais do que a elevada tensão emocional do público. Se existem soluções, é preciso investigá-las em todos os níveis, dentro e fora do local do espetáculo. Algumas delas, como a rebelião de Serafim, são exterminadas ao nível da fábula, nos domínios da ficção. E, se podem ser sabotadas por uma representação, mais facilmente serão vulneráveis diante dos poderosos e organizados mecanismos da repressão. $O$ canhão no quintal é apenas um canhão em um quintal. Enquanto isso, o sistema se afirma na habilidade de manipular quantidades enormes de seres.

Se a reação pode começar pela célula, Gracias Señor mostra a ineficiência da célula diante da compacta tessitura do organismo completo. A menos que essa célula esteja preparada para ligar-se até a confecção de um outro tipo de tecido, resistente e amplo como seu opositor.

O que fazemos no teatro? Como? Por que? Para que? Há uma certa margem de previsibilidade nas respostas do público. Através de uma atuação anterior, o Oficina sabe que pode contar com o "público do Oficina." Arriscam assim uma posição consolidada ao longo de uma década de participação ativa no teatro brasileiro. Sabem que são importantes para a história desse teatro. Sabem que o público que os acompanha não é o mesmo que aplaude as comédias importadas da Broadway. E utilizam conscientemente essa informação.

Há estudantes, professores universitários, advogados etc. Quase sempre liberais, com abertura para acompanhar as experiências de vanguarda. Perguntar a esse público o que faz no teatro é mais que uma investigação sobre a finalidade da arte. É questionar um momento determinado da vida dessas pessoas. Não se trata de discutir teoricamente o teatro, mas de discutir o presente do espectador, o que está acontecendo em uma noite de lazer ou de cultura.

Gracias Señor trabalha sobre o espaço que o espectador reservou na sua vida para seguir passivamente a evolução do Oficina. Perguntar, no caso, é abandonar a posição de criador ativo para um consumidor passivo. Com isso o Oficina se propõe também a ser discutido. O público tem todo o direito de confrontá-lo e ameaçar a posição confortável de artistas de excelente nível. 
Mas a situação é ambígua. Porque sabemos que o espetáculo continua, independentemente da resposta do espectador não iniciado do Oficina. Sempre uma claque de fiéis saudosistas obrigará, em nome das realizações do passado, à continuidade do espetáculo. Desta vez não se trata da inauguração de um estilo, de outro tropicalismo. Para sobreviver e realizar-se, o espetáculo necessita da atuação do público.

Com a garantia de um público já constituído, Gracias Señor se desenvolve sobre o impacto da confrontação com a plateia.

As perguntas criaram um estado anímico de inquietação e insegurança. Durante o decorrer do espetáculo o espectador sabe que a qualquer momento pode ser solicitado para uma participação. E que será forçado a utilizar não só a situação estar-no-teatro, como toda a experiência de vida que o conduziu até esse lugar. 